\title{
Cerebral folate deficiency and CNS inflammatory markers in Alpers disease
}

\author{
Oswald Hasselmann ${ }^{\mathrm{a}, *}$, Nenad Blau ${ }^{\mathrm{b}, *}$, Vincent T. Ramaekers ${ }^{\mathrm{c}}$, Edward V. Quadros ${ }^{\mathrm{d}}$, J.M. Sequeira ${ }^{\mathrm{d}}$, \\ Markus Weissert ${ }^{\mathrm{a}}$ \\ ${ }^{a}$ Department of Pediatric Neurology, Ostschweizer Kinderspital, Claudiusstrasse 6, CH 9006 St. Gallen, Switzerland \\ ${ }^{\mathrm{b}}$ Division of Clinical Chemistry and Biochemistry, University Children's Hospital, Zürich, Switzerland \\ ${ }^{\mathrm{c}}$ Department of Pediatric Neurology, University Hospital Liège, Belgium \\ ${ }^{\mathrm{d}}$ Departments of Medicine and Cell Biology, SUNY Downstate Medical Centre, Brooklyn, NY, USA
}

\section{A R T I C L E I N F O}

\section{Article history:}

Received 2 August 2009

Received in revised form 19 August 2009

Accepted 19 August 2009

Available online 22 August 2009

\section{Keywords}

Mitochondria

Folate-antibodies

Epilepsy

Neopterin, Cytokines

POLG

\begin{abstract}
A B S T R A C T
We describe a 3.5-year-old female with Alpers disease with a POLG genotype of p.A467T/p.G848S and with a lethal outcome. Laboratory investigation revealed elevated CSF neopterin, IL-6, IL-8, IFN- $\gamma$, reduced CSF 5-methyltetrahydrofolate (5MTHF), and increased serum as well as CSF folate receptor blocking autoantibodies. Treatment with oral Leucovorine (5-formyl-tetrahydrofolate) was initiated at $0.25 \mathrm{mg} / \mathrm{kg}$ bid, and later increased to $4 \mathrm{mg} / \mathrm{kg}$ bid. Under treatment CSF levels of 5MTHF, seizure frequency and communicative abilities improved. Over a time span of 17 months, CSF levels of IL-6 and IFN- $\gamma$ decreased, levels of folate receptor blocking autoantibodies continued to raise, whereas CSF IL- 8 remained elevated 1500-fold above normal. The child died without apparent stress at the age of 5.5 years. Alpers disease, a neurodegenerative disease usually presents in the first years of life as a progressive encephalopathy with multifocal myoclonic seizures, developmental regression, cortical blindness and early death. The underlying genetic defect has been attributed to mutations of the catalytic subunit of the mitochondrial DNA polymerase- $\gamma$ leading to an organ-specific mitochondrial DNA depletion syndrome with reduced activity of respiratory chain enzyme complexes in the brain and the liver. A curative therapy is not available. This case report of Alpers disease provides new insights into the pathophysiology of Alpers disease, where mitochondrial dysfunction in conjunction with inflammatory cytokines and blocking folate receptor autoantibodies may lead to a secondary cerebral folate deficiency syndrome. The treatment of the latter provides relief to the patient without stopping the underlying disease.
\end{abstract}

(c) 2009 Elsevier Inc. All rights reserved.

\section{Introduction}

Alpers disease (OMIM 203700), [1] a spongiform cerebral degenerative disease affects the cerebral cortex, the cerebellum, the basal ganglia and the brain stem. The incidence of Alpers disease is estimated between $1 / 100,000$ and $1 / 250,000$. The affected patients present with a developmental retardation followed by regression, intractable epilepsy, movement disorders, abnormal respiration and at times cortical atrophy and liver dysfunction [2]. Biochemical findings can disclose a dysfunction of the citric acid cycle due to reduced activity of respiratory chain enzymes attributable to mutations of the gene encoding the mitochondrial DNA polymerase enzyme $(P O L G)^{1}[3]$. There are so far no biochem-

\footnotetext{
* Corresponding authors. Fax: +41 712437367 (O. Hasselmann).

E-mail addresses: oswald.hasselmann@kispisg.ch (O. Hasselmann), nenad. blau@kispi.uzh.ch (N. Blau).

1 Abbreviations used: EEG, electroencephalography; IL-6, interleukin-6; IL-8, interleukin-8; IFN- $\gamma$, interferon-gamma; mtDNA, mitochondrial DNA; 5MTHF, 5-methyltetrahydrofolate; MTHFR, methylenetetrahydrofolate reductase; POLG, polymerasegamma.
}

icals or inflammatory markers reported and there is no known effective therapy. Valproate as an anticonvulsant drug should be avoided since it is known to induce hepatic failure. Here, we report on novel biochemical findings in a girl with Alpers disease complicated by cerebral folate deficiency and potential treatment options with folinic acid.

\section{Materials and methods}

\section{Case report}

A 31/2-year-old girl presented with acute onset of status epilepticus and somnolence. EEG activity was severely suppressed with focal spike-waves over the temporal regions. The status was initially interrupted by the use of a combination of anticonvulsant drugs but re-emerged in the following days and months and could at times only be suppressed by anesthetic agents.

The girl is the only child of healthy unrelated parents. No progressive neurological diseases are known in the wider family. At the age of 30 months the girl was diagnosed with mental and 
motor retardation of about 8-12 months. A video taken by the local pediatrician at age $2 \frac{1}{2}$ years showed an ataxia with dysmetria and muscular hypotonia. Her IQ was estimated at a value of 75 . At the age of 2 years she had developed simple speech, her weight and height curves never surpassed the 3 rd percentile. She had no specific dysmorphic features nor increased susceptibility to infectious diseases. The child died without apparent neurodegeneration at the age of 5.5 years. An autopsy was not obtained.

\section{Neuroimaging}

Cranial computer tomography (CCT) on day two of the acute disease was compatible with a generalized brain edema, whereas magnetic resonance imaging (MRI) of the CNS at the same time showed no abnormalities of either white or grey matter. A second MRI 3 months after disease onset showed mild cerebral atrophy and an $8 \times 11 \mathrm{~mm}$ ischemic lesion in the left thalamus.

\section{Laboratory investigations}

Laboratory or skin examinations excluded the following diseases: sphingolipidoses, gangliosidoses, disorders of glycolysation, ceroid lipofuscinosis type 1 and 2, Lafora disease, myoclonic epilepsy with ragged red fibers, and pyridoxine/pyridoxal-5'-phosphat-dependent epilepsy. Normal laboratory values were obtained for liver enzymes, coagulation parameters, lactate, lactate-pyruvate ratio, vitamin B12, homocysteine, folic acid (serum), organic acids (urine), amino acids (urine, serum) acylcarnitines (dried blood), neopterin, and biopterin (urine). Ammonia was increased intermittently up to three times the normal values (143 $\mu \mathrm{mol} / \mathrm{L}$, normal: $10-48 \mu \mathrm{mol} / \mathrm{L})$. Cerebral spinal fluid (CSF) analysis was normal for white blood count, amino acids, bacterial or viral infections. Lactate and protein were elevated (lactate: $3.1 \mathrm{mmol} / \mathrm{L}$; normal: $0.8-2.3 \mathrm{mmol} / \mathrm{L}$, protein: $2.9 \mathrm{~g} / \mathrm{l}$, normal: $0.1-0.3 \mathrm{~g} / \mathrm{L})$

Neurotransmitter metabolites and folates in CSF were investigated as described previously [4]. CSF and folate receptor (FR) autoantibodies of the blocking type were measured in CSF and plasma [5].

\section{Results}

\section{CSF investigations}

Neurotransmitter and folate analysis of CSF showed a markedly decreased 5-methyltetrahydrofolate (5MTHF) concentration, in the presence of increased neopterin, interleukin-6 (IL-6), interleukin-8 (IL-8) and interferon- $\gamma($ IFN- $\gamma$ ) (Table 1 ).

Folate receptor (FR) autoantibodies of the blocking type were present at week 32 and week 52 in serum $(0.34 \mathrm{pmol} / \mathrm{mL}$, $0.98 \mathrm{pmol} / \mathrm{mL}$; normal: $<0.2 \mathrm{pmol} / \mathrm{mL}$ ) and at 52 weeks in CSF (1.2 pmol $/ \mathrm{mL}$; normal: $<0.2 \mathrm{pmol} / \mathrm{mL}$ ) (Table 1 ). The two metabo- lites of dopamine and serotonin homovanillic acid (HVA) and 5hydroxyindoleacetic acid (5HIAA) as well as 3-o-methyl-dopa (3OMD) were at the upper normal range or even increased at all times, independently of the 5MTFH therapy.

Protein content in CSF wars repeatedly above expected values (1.3; $1.9 ; 2.9$, normal: $0.1-0.3 \mathrm{~g} / \mathrm{L})$.

\section{Muscle biopsy}

Respiratory chain enzyme analysis performed on quadriceps muscle showed normal activities of complexes I, II, II + III, III, and IV compared to the mitochondrial marker enzyme citrate synthase (Friedrich Baur Institute, University of Munich, Germany). Mitochondrial DNA (mtDNA) quantification performed on the muscle biopsy material was not done.

\section{Epilepsy and electroencephalogram}

Repeated status epilepticus required invasive ventilation and at times the use of more than four anticonvulsant drugs simultaneously. Valproic acid as an anticonvulsant agent was not administered since an underlying metabolic disturbances could not be excluded and the EEG pattern with unilateral occipital rhythmic high-amplitude delta with superimposed polyspikes was suggestive of for Alpers disease [6].

\section{Molecular examination}

Molecular testing revealed a compound heterozygous mutation in the POLG-1 gene on chromosome 15q25. A missense mutation in the polymerase domain in exon 16 leading to p.G848S exchange (c.2542G > A) and a missense mutation in the linker region in exon 7 leading to p.A467T exchange (c.1399G > A) was identified. The first mutation was derived from the mother the latter from the father of the child, both being healthy. Both mutations have previously been described as compound heterozygosity in patients with Alpers disease [3].

\section{Treatment}

Faced with the deteriorating clinical situation of an intractable epileptic syndrome impressing as epilepsia partialis continua, refractory to common antiepileptic drugs, we asked for parental consent to administer pharmacologic doses of folinic acid (5-formyltetrahydrofolate, Leucovorine) in order to compensate for the intracerebral folate deficiency. Treatment was started with a daily oral dose of $2 \times 0.25 \mathrm{mg} / \mathrm{kg}$ body weight and later increased to $2 \times 4 \mathrm{mg} / \mathrm{kg}$ /body weight).

A remarkable clinical improvement could be observed thereafter. After 2 weeks we could start to reduce the anticonvulsant treatment from four to two drugs. For 17 months under a combined anticonvulsant drug regime with Phenobarbitone and Viga-

Table 1

Neurotransmitter metabolites, folates, cytokines in CSF and autoantibodies against folate receptor in serum and CSF of a patient with Alpers disease.

\begin{tabular}{|c|c|c|c|c|c|c|c|c|c|c|c|}
\hline \multirow[t]{2}{*}{ Weeks since disease onset at 3.5 years } & \multirow[t]{2}{*}{$\begin{array}{l}\text { 5HIAA } \\
(\mathrm{nmol} / \mathrm{L})\end{array}$} & \multirow[t]{2}{*}{$\begin{array}{l}\text { HVA } \\
(\mathrm{nmol} / \mathrm{L})\end{array}$} & \multirow[t]{2}{*}{$\begin{array}{l}30 M D \\
(\mathrm{nmol} / \mathrm{L})\end{array}$} & \multirow[t]{2}{*}{$\begin{array}{l}\text { 5MTHF } \\
(\mathrm{nmol} / \mathrm{L})\end{array}$} & \multirow[t]{2}{*}{$\begin{array}{l}\text { Neo } \\
(\mathrm{nmol} / \mathrm{L})\end{array}$} & \multirow[t]{2}{*}{$\begin{array}{l}\text { Bio } \\
(\mathrm{nmol} / \mathrm{L})\end{array}$} & \multirow[t]{2}{*}{$\begin{array}{l}\text { IL-6 } \\
(\mathrm{pg} / \mathrm{mL})\end{array}$} & \multirow[t]{2}{*}{$\begin{array}{l}\text { IL-8 } \\
\text { (pg/mL) }\end{array}$} & \multirow[t]{2}{*}{$\begin{array}{l}\text { IFN- } \gamma \\
(\mathrm{pg} / \mathrm{mL})\end{array}$} & \multicolumn{2}{|c|}{$\begin{array}{l}\text { FRAA } \\
(\mathrm{pmol} / \mathrm{mL})\end{array}$} \\
\hline & & & & & & & & & & Serum & CSF \\
\hline 8 & 406 & 1167 & 122 & 22.9 & 78.3 & 20.1 & $>300$ & n.d. & 0.7 & n.d. & n.d. \\
\hline $12^{*}$ & 259 & 882 & 130 & 73.1 & 100.5 & 18.0 & 23.4 & n.d. & n.d. & n.d. & n.d. \\
\hline $32^{*}$ & 529 & 955 & 205 & 58.2 & 57.6 & 13.9 & 5.7 & n.d. & 1.3 & 0.34 & n.d. \\
\hline $52^{*}$ & 402 & 1121 & 145 & 20.5 & 84.5 & 15.0 & 7.5 & 152 & 0.2 & 0.98 & 1.20 \\
\hline Normal: 2-4 years & $105-299$ & $211-871$ & $<50$ & $63-111$ & $9-30$ & $10-30$ & $<3.1$ & $<0.1$ & $<0.1$ & $<0.2$ & \\
\hline
\end{tabular}

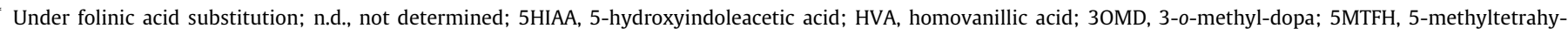
drofolate; Neo, neopterin; Bio, biopterin; IL-6, interleukin-6; IL-8, interleukin-8; IFN- $\gamma$, interferon-gamma; FRAA, folate receptor autoantibodies. 
batrin no more status epilepticus and a marked reduction of focal seizures could be witnessed. During the months of folinic acid substitution therapy the EEG remained highly pathological, although high-amplitude slow waves decreased and specific epileptic activity appeared less pronounced.

On the clinical side we witnessed an improvement of communication skills of the child. Whereas before there was no interaction possible between the parents and their daughter, a prompt response of the child could be observed when the child was spoken to or touched by the parents. The girl was able to indicate physical discomfort such as a full bladder. Cortical blindness seemed much less apparent, swallowing difficulties were diminished. At the age of $5 \frac{1}{2}$ the girl passed away without an apparent deterioration.

During folinic acid supplementation follow-up investigations showed a rise in CSF FR-autoantibody titers coinciding with a decrease of 5MTHF levels prompting us to increase the folinic acid doses. At disease onset IL- 6 was increased 3000 times the expected value and almost approached normal values in the course of the disease, whereas IL-8 still remained elevated with an increment at 1500 times the expected value (Table 1 ).

\section{Discussion}

Although the understanding of the molecular defects of Alpers disease has increased over recent years, the exact relationship between the molecular defect and the phenotype remains very complex. Clayton described in 1982 how the 16569-bp human mitochondrial genome is replicated and repaired by DNA polymerase- $\gamma(P O L G)$ [7]. The first pathogenic mutations of POLG were described in 2001 in families with autosomal dominant chronic progressive external ophthalmoplegia [8]. Tissue-specific mtDNA deletions were later identified as causes of deficiencies in mitochondrial oxidative phosphorylation [9].

Different and overlapping disease entities ranging from psychiatric disturbances to primary neurological diseases and endocrine disturbances have been associated with POLG mutation. Mutations in POLG gene account for approximately $90 \%$ of the classical phenotype of Alpers disease [10]. One in 50 people are thought to be silent heterozygote carriers of POLG mutations.

Most cases with childhood onset Alpers disease are associated with at least one mutation in the linker region of the POLG gene and one in the polymerase domain. The most common disease mutation in $P O L G$ associated with Alpers disease, as in our patient, is the G-to-A mutation at nucleotide 1399 in exon 7 of POLG causing an alanine to threonine amino acid substitution at codon 467 . In the Belgian population the p.A467T mutation has been observed at a frequency of $0.6 \%$ without showing clinical signs [6].

In Alpers disease the p.A467T mutation is either homozygous or paired in trans with other mutations in POLG. In the case of compound heterozygosity there is a polymerase activity of only $4 \%$ comparing to the wild-type DNA [11]. It is thus the nature of the mutation in the second POLG allele in compound heterozygous patients that influences the severity and type of the disease. More prolonged disease courses with less severe symptoms have been described and seemed to be associated with a homozygous mutation $[10,12]$.

The symptomatic epilepsy in Alpers disease is usually refractory to common antiepileptic drug treatment. Epileptic status is often the terminating event. The use of valproic acid as an anticonvulsant drug has repeatedly led to a terminal hepatic failure and should be avoided [13].

The natural course of the disease is progressive with death occurring in most cases within 6-12 months after the onset of the disease. A gene dosage effect is thought to be an important determinant for age of onset, the severity, and course of the disease.

We justified giving 5-formyltetrahydrofolate (calcium folinate) in the form of Leucovorin taking the following into consideration: Folic acid is a water soluble vitamin that is converted into various reduced forms involved in synthesis of purine and pyrimidine bases, methylation of genomic DNA, conversion of homocysteine to methionine, transfer of methyl-groups, and formation of the active methyl-group donor $S$-adenosylmethionine, used in various methylation reactions. Furthermore folates exert a direct influence on brain function through the enhanced biosynthesis of phospholipids and hence myelination.

The physiological plasma folate form 5MTHF is actively transferred across the blood-brain barrier by a folate receptor mediated endocytotic process in choroid epithelial cells and reaches 2-4-fold higher concentration in the spinal fluid as compared to serum.

A balanced diet usually provides sufficient quantities of folate to the CNS. However, the presence of folate receptor autoantibodies, oxidative stress and secondary inflammatory responses are able to block folate transfer across the choroid plexus to the CNS. Such primary and secondary forms of cerebral folate deficiency (CFD) with an encephalopathic symptomatology have extensively been described in the infantile-onset CFD syndrome [14], mitochondrial encephalopathies [15], Kearns-Sayre syndrome [16], Rett syndrome $[17,18]$, and Aicardi-Goutières syndrome [19]. The use of antifolate drugs in rare inborn errors of metabolism like deficiency of dihydropteridine reductase, methylenetetrahydrofolate reductase, aromatic aminoacid decarboxylase and 3-phosphoglycerate dehydrogenase should be excluded [14].

The low CSF levels of 5MTHF in our patient can be explained by blocked transport across the blood-brain barrier due to the presence of FR autoantibodies as well as by increased utilization and catabolism of 5MTHF due to oxidative stress [16]. Another explanation may be a defective transport due to ATP depletion in the choroid plexus, as seen in Kearns-Sayre syndrome.

Of interest are the relative high concentrations of neurotransmitter metabolites 5HIAA, HVA, and 3OMD in CSF. Both serotonin and catecholamines metabolism are intimately tied to both mitochondria and inflammation. An inflammatory event with IFN- $\gamma$ stimulation is known to lead to both increased tryptophan degradation (via indoleamine dioxygenase) and neopterin production (via GTP cyclohydrolase I) [20].

The substitution with high doses of folinic acid will increase $5 \mathrm{MTHF}$ plasma concentrations even in the presence of blocking FR autoantibodies facilitating thereby an increased uptake of 5MTHF into the CSF compartment via the folate carrier. To treat the cerebral folate deficiency we have chosen an initial oral dose of $2 \times 0.25 \mathrm{mg} / \mathrm{kg}$ body weight Leucovorine and later adapted the dose to reach age specific levels of CSF 5MTHF. We refrained from further augmenting the dose, since it is known that high folic acid doses can decrease blood levels of anticonvulsant drugs such as Phenobarbital and thereby potentially interfere with seizure control [21]. The medication was well tolerated and followed by a marked improvement of the child, though high CSF IL-8 levels reminded of the persisting pro-inflammatory process.

Considering the possible mechanism of the observed effects, we speculate that repletion of folates within the CNS could lead to a partial repair of previously deranged folate-dependant pathways and mitochondrial dysfunction. To our knowledge in disorders of mtDNA deletions the role of folinic acid substitution has not been evaluated. At the moment we do not know to what extent the production of folate receptor autoantibodies in Alpers disease contribute to its pathophysiology, whether it represents a consistent finding or it is merely an epiphenomenon of the cerebral inflammatory response. 
The unraveling of insufficient polymerase- $\gamma$ activity and mitochondrial depletion as the underlying cause of Alpers disease has been followed by many case reports of the natural evolution of this devastating disease for which a treatment to alleviate symptoms is still lacking. Following published experience of the positive effects of increasing cerebral folate in those patients with a decreased CSF $5 \mathrm{MTHF}$ concentration we observed for a prolonged period, a remarkable clinical improvement after folinic acid substitution. Our encouraging experience provides an impetus to further clinical and laboratory studies.

\section{Acknowledgments}

This work was supported in part by The Swiss National Science Foundation Grant No. 3100A0-1199852/1 (to N.B.) and HD051880 from the National Institutes of Health, USA (to E.V.Q.).

\section{References}

[1] B.J. Alpers, Diffuse progressive degeneration of the grey matter of the cerebrum, Arch. Neurol. Psychiatr. (1931) 469-505.

[2] N. Gordon, Alpers syndrome: progressive neuronal degeneration of children with liver disease, Dev. Med. Child Neurol. 48 (2006) 1001-1003.

[3] K.V. Nguyen, F.S. Sharief, S.S. Chan, W.C. Copeland, R.K. Naviaux, Molecular diagnosis of Alpers syndrome, J. Hepatol. 45 (2006) 108-116.

[4] N. Blau, M. Duran, K.M. Gibson, Laboratory Guide to the Methods in Biochemical Genetics, Springer-Verlag, Berlin, Heidelberg, 2008.

[5] V.T. Ramaekers, S.P. Rothenberg, J. Sequeira, T. Opladen, N. Blau, E.V. Quadros, J. Selhub, Autoantibodies against folate receptors of the choroid plexus block folate uptake and cause cerebral folate deficiency in childhood, NEJM 352 (2005) 1985-1991.

[6] A.H. Hakonen, G. Davidzon, R. Salemi, L.A. Bindoff, G. Van Goethem, S. Dimauro, D.R. Thorburn, A. Suomalainen, Abundance of the POLG disease mutations in Europe, Australia, New Zealand, and the United States explained by single ancient European founders, Eur. J. Hum. Genet. 15 (2007) 779-783.

[7] D.A. Clayton, Replication of animal mitochondrial DNA, Cell 28 (1982) 693-705.

[8] M. Hirano, S. DiMauro, ANT1, Twinkle, POLG, and TP: new genes open our eyes to ophthalmoplegia, Neurology 57 (2001) 2163-2165.
[9] G. Van Goethem, B. Dermaut, A. Lofgren, J.J. Martin, C. Van Broeckhoven, Mutation of POLG is associated with progressive external ophthalmoplegia characterized by mtDNA deletions, Nat. Genet. 28 (2001) 211-212.

[10] R. Horvath, G. Hudson, G. Ferrari, N. Futterer, S. Ahola, E. Lamantea, H. Prokisch, H. Lochmuller, R. McFarland, V. Ramesh, T. Klopstock, P. Freisinger, F. Salvi, J.A. Mayr, R. Santer, M. Tesarova, J. Zeman, B. Udd, R.W. Taylor, D. Turnbull, M. Hanna, D. Fialho, A. Suomalainen, M. Zeviani, P.F. Chinnery, Phenotypic spectrum associated with mutations of the mitochondrial polymerase gamma gene, Brain 129 (2006) 1674-1684.

[11] S.S. Chan, M.J. Longley, W.C. Copeland, The common A467T mutation in the human mitochondrial DNA polymerase (POLG) compromises catalytic efficiency and interaction with the accessory subunit, J. Biol. Chem. 280 (2005) 31341-31346.

[12] R.K. Naviaux, K.V. Nguyen, POLG mutations associated with Alpers' syndrome and mitochondrial DNA depletion, Ann. Neurol. 55 (2004) 706-712.

[13] B.N. Harding, N. Alsanjari, S.J. Smith, C.M. Wiles, D. Thrush, D.H. Miller, F. Scaravilli, A.E. Harding, Progressive neuronal degeneration of childhood with liver disease (Alpers' disease) presenting in young adults, J. Neurol. Neurosurg. Psychiatry 58 (1995) 320-325.

[14] V.T. Ramaekers, N. Blau, Cerebral folate deficiency, Dev. Med. Child Neurol. 46 (2004) 843-851.

[15] M. Pineda, A. Ormazabal, E. Lopez-Gallardo, A. Nascimento, A. Solano, M.D. Herrero, M.A. Vilaseca, P. Briones, L. Ibanez, J. Montoya, R. Artuch, Cerebral folate deficiency and leukoencephalopathy caused by a mitochondrial DNA deletion, Ann. Neurol. 59 (2006) 394-398.

[16] V.T. Ramaekers, J. Weis, J.M. Sequeira, E.V. Quadros, N. Blau, Mitochondrial complex I encephalomyopathy and cerebral 5-methyltetrahydrofolate deficiency, Neuropediatrics 38 (2007) 184-187.

[17] V.T. Ramaekers, H. Steen-Ingemann, J. Holm, T. Opladen, J. Senderek, M. Häusler, G. Heimann, B. Fowler, R. Maiwald, N. Blau, Reduced folate transport to the brain in Rett syndrome, Neurology 61 (2003) 506-514.

[18] A. Ormazabal, R. Artuch, M.A. Vilaseca, A. Aracil, M. Pineda, Cerebrospinal fluid concentrations of folate, biogenic amines and pterins in Rett syndrome: treatment with folinic acid, Neuropediatrics 36 (2005) 380-385.

[19] N. Blau, L. Bonafé, I. Krägeloh-Mann, B. Thöny, L. Kierat, M. Häusler, V.T. Ramaekers, Cerebrospinal fluid pterins and folates in Aicardi-Goutières syndrome: a new phenotype, Neurology 61 (2003) 642-648.

[20] B. Widner, A. Laich, B. Sperner-Unterweger, M. Ledochowski, D. Fuchs, Neopterin production, tryptophan degradation, and mental depression what is the link?, Brain Behav Immun. 16 (2002) 590-595.

[21] L. Guidolin, A. Vignoli, R. Canger, Worsening in seizure frequency and severity in relation to folic acid administration, Eur. J. Neurol. 5 (1998) 301303. 